\title{
A NOVA DIMENSÃO DOS DIREITOS HUMANOS E SUA RELAÇÃO COM A DIGNIDADE DA PESSOA HUMANA
}

\author{
THE NEW DIMENSION OF HUMAN RIGHTS AND ITS RELATION TO HUMAN DIGNITY
}

Rogerio Taiar*

\begin{abstract}
Resumo:
O presente estudo analisa a nova dimensão dos Direitos Humanos e da dignidade da pessoa humana, como desdobramentos dos direitos fundamentais assegurados constitucionalmente e não passíveis de alterações, em razão de constituírem-se em verdadeiras cláusulas pétreas da nossa Carta Magna. O texto apresenta os conteúdos positivo e negativo do princípio da igualdade e sua íntima relação com a dignidade da pessoa humana, valor supremo e fundamento do nosso Estado Democrático de Direito.

Palavras-chave: Nova dimensão. Dignidade da Pessoa Humana. Direitos Humanos. Estado Democrático de Direito.
\end{abstract}

\begin{abstract}
:
This study analyses the new dimension of Human Rights and human dignity, as a deployment of the preserved and unamovable constitutional fundamental rights, because it represents basic clauses of our Constitution. The text presents the positive and negative contents of the equality principle and its close relation with the human dignity, the supreme value and fundamentals of democratic rule of law.
\end{abstract}

Keywords: New Dimension. Individual Dignity. Human Rights. Democratic Rule of Law.

\section{Introdução}

A afirmação dos Direitos Humanos irá ocorrer através das revoluções burguesas dos séculos XVIII e XIX, institucionalizando o ideal igualitarista segundo o qual todos os seres humanos são dotados da mesma dignidade.

Nesse sentido, afirma Maria Covre que:

são com as revoluções burguesas, particularmente à Revolução Francesa estabelecem-se as Cartas Constitucionais, que se opõem ao processo de normas difusas e indiscriminadas da

\footnotetext{
Doutor em Direitos Humanos pela Faculdade de Direito da Universidade de São Paulo. Mestre em Positivação e Concretização Jurídica dos Direitos Humanos pelo Centro Universitário FIEO (UNIFIEO) SP. Professor de Direito Internacional e de Direitos Humanos da Universidade Paulista (UNIP) e da Escola Paulista de Advocacia do Instituto dos Advogados de São Paulo (IASP).
} 
sociedade feudal e às normas arbitrárias do regime monárquico ditatorial, anunciando uma relação jurídica centralizada, o chamado Estado de Direito. Este surge para estabelecer direitos iguais a todos os homens, ainda que perante a lei, e acenar com o fim da desigualdade a que os homens sempre foram relegados. Assim, diante da lei, todos os homens passaram a ser considerados iguais, pela primeira vez na história da humanidade. Esse fato foi proclamado principalmente pelas constituições francesa e norte americana, e reorganizado e ratificado, após a II Guerra Mundial, pela Organização das Nações Unidas (ONU), com a Declaração Universal Dos Direitos do Homem (1948). ${ }^{1}$

Em sua origem, os Direitos Humanos surgem como antítese aos privilégios, reivindicando a igual dignidade dos indivíduos e, em conseqüência, impondo ao Estado o dever de editar regras gerais e impessoais, ancorado no pressuposto de que as aptidões intelectuais, a capacidade, o mérito de cada um constituiria requisitou único através do qual seriam distribuídos os bens e vantagens, com base na qual se desenvolveriam as potencialidades humanas, rumo a uma sociedade meritocrática, ao menos no plano formal.

Consagrado como valor supremo universal, os Direitos Humanos requerem tanto uma postura de não intervenção como também uma postura de atuação do Estado, esta através de regras e leis de não-discriminação, atendendo à realidade social dos indivíduos.

\section{Princípios Jurídicos}

O Direito pode ser concebido como um verdadeiro sistema formado por regras e princípios. Por princípio deve-se entender uma espécie de norma jurídica diversa das meras regras, e estabelecem pontos de partida para aplicação, interpretação e concretização do direito.

Para Miguel Reale, os princípios gerais de direito são enunciações normativas de valor genérico, que irão condicionar e orientar a compreensão do ordenamento jurídico, que para a sua aplicação e integração, quer para a elaboração de novas normas, e, dessa forma, cobrem tanto o campo da pesquisa pura do direito quanto o de sua utilização prática. ${ }^{2}$

Na lição de Geraldo Ataliba, tem-se que:

os princípios são as linhas mestras, os grandes nortes, as diretrizes magnas do sistema jurídico. Apontam os rumos a serem seguidos por toda a sociedade e obrigatoriamente perseguidos pelos órgãos do governo (poderes constituídos).

\footnotetext{
COVRE, Maria de Lourdes Manzini. O que é cidadania. São Paulo: Brasiliense, 1993. p. 17.
}

2 REALE, Miguel. Lições Preliminares de Direito. São Paulo: Editora Saraiva, 2001. p.306-307. 
Eles expressam a substância última do querer popular, seus objetivos e desígnios, as linhas mestras da legislação, da administração e da jurisdição. Por estas não podem ser contrariados; têm que ser prestigiados até as últimas conseqüências. ${ }^{3}$

Sustenta Dworkin, que o Direito não é apenas um conjunto de regras primárias e secundárias, mas é também constituído por princípios, sendo que Dworkin, irá propor uma definição negativa de princípio, que irá depender da distinção entre as regras e outros padrões. Desta forma, os princípios são um conjunto de normas outras que não são regras jurídicas.

Para Dworkin, o termo princípio, de modo mais específico, diz respeito a um tipo de norma cujo respeito é um requisito de justiça ou equidade ou alguma outra dimensão da moralidade. De forma exemplificativa, a determinação de que ninguém deve beneficiar-se da sua própria torpeza funciona como um princípio, enquanto que a determinação de que os acidentes de trânsito devem diminuir é norma que funciona como diretriz política. ${ }^{4}$

\subsection{Distinção entre princípios e regras}

A distinção entre princípios e regras é uma distinção lógica. Ambos são conjuntos de normas (standards) que apontam para decisões particulares sobre obrigações jurídicas numa particular circunstância. Mas se diferenciam no caráter da direção que apontam. As regras são aplicáveis na forma do tudo-ou-nada, ou seja, são disjuntivas, aplicam-se ou não se aplicam ao caso concreto e quando ocorrem conflitos entre as normas temos a antinomia jurídica própria ou real.

Já os princípios, embora muito se pareçam com as regras, não indicam uma conseqüência legal que automaticamente se segue quando as condições dadas se realizam. Um princípio apresenta uma razão que aponta para uma direção, porém, não exige uma decisão específica naquele mesmo sentido (apontado). Ilustrando, se um homem vai receber algo como produto direto de uma conduta ilegal, o princípio de que ninguém deve se beneficiar do seu próprio erro precisa ser levado em conta, mas há outros princípios e políticas apontando para uma outra direção: a política da segurança do título, por exemplo, ou o princípio da legalidade. Um princípio pode não prevalecer, no entanto não significa que não seja um princípio do nosso Direito. Trata-se de um dos princípios que os

3 ATALIBA, Geraldo. República e Constituição. São Paulo: Malheiros Editores, 1998. p. 34.

4 TAVARES, Quintino L. C. Dworkin: princípios e diretrizes políticas: uma abordagem introdutória. Jusfilosofia. Florianópolis/SC, jul./02. http://br.geocities.com/jusfilosofia/hermeneutica/dworkin1.html. 
funcionários do sistema precisam levar em conta, se for relevante, como uma consideração que aponta para uma outra direção. ${ }^{5}$

A diferenciação entre regras e princípios foi muito bem formulada por Canotilho $^{6}$, que diz que saber como distinguir, no âmbito do superconceito norma, entre regras e princípios, é uma tarefa particularmente complexa, apresentando os seguintes critérios:

a) O grau de abstração: os princípios são normas com um grau de abstração relativamente elevado; de modo diverso, as regras possuem uma abstração relativamente reduzida.

b) Grau de determinabilidade na aplicação do caso concreto: os princípios, por serem vagos e indeterminados, carecem de mediações concretizadoras (do legislador? do juiz?), enquanto as regras são suscetíveis de aplicação direta.

c) Caráter de fundamentalidade no sistema de fontes do direito: os princípios são normas de natureza ou com um papel fundamental no ordenamento jurídico devido à sua posição hierárquica no sistema das fontes (ex: princípios constitucionais) ou a sua importância estruturante dentro do sistema jurídico (ex: princípio do Estado de Direito).

d) Proximidade da idéia de direito: os princípios são standards juridicamente vinculantes radicados nas exigências de justiça (Dworkin) ou na idéia de direito (Larenz); as regras podem ser normas vinculantes com um conteúdo meramente formal.

e) Natureza normogenética: os princípios são fundamento de regras, isto é, são normas que estão na base ou constituem a ratio de regras jurídicas, desempenhando, por isso, uma função normogenética fundamentante. ${ }^{7}$

Os princípios podem desempenhar uma função argumentativa, denotando a ratio legis de uma disposição e estabelecendo a sua interpretação ou fazer a revelação de normas que não são expressas por qualquer enunciado legislativo, possibilitando aos juízes, o desenvolvimento, integração e complementação do direito, ou seja, os princípios apresentam uma dimensão multifacional.

Qualitativamente, segundo Canotilho ${ }^{8}$, como verdadeiras normas jurídicas, os princípios apresentam as seguintes diferenças em relação a outras categorias de normas - regras jurídicas, evidenciadas nos seguintes aspectos:

Ibid.

6 CANOTILHO, José Joaquim Gomes. Curso de direito constitucional. Coimbra: Almedina, 1993. p. 166168.

7 Ibid., p. 166-168.

8 Ibid., p. 166-168. 
(1) os princípios são normas jurídicas impositivas de uma otimização, compatíveis com vários graus de concretização, consoante os condicionalismos fáticos e jurídicos; as regras são normas que prescrevem imperativamente uma exigência (impõem, permitem ou proíbem) que é ou não é cumprida (...); a convivência dos princípios é conflitual; a convivência de regras é antinômica; os princípios coexistem; as regras antinômicas excluem-se.

(2) Por constituírem exigências de otimização, os princípios permitem o balanceamento de valores e interesses (não obedecendo, como as regras jurídicas, a lógica do tudo ou nada), consoante o seu peso e a ponderação de outros princípios eventualmente conflitantes; as regras não deixam espaço para qualquer outra solução, pois se uma regra vale (tem validade) deve cumprir-se na exata medida das suas prescrições, nem mais nem menos.

(3) em caso de conflito entre princípios, este podem ser objeto de ponderação, de harmonização, pois eles contem apenas exigências ou standards que, em primeira linha (prima facie), devem ser realizados; as regras contêm fixações normativas definitivas, sendo insustentável a validade simultânea de regras contraditórias.

(4) os princípios suscitam problemas de validade e peso (importância, ponderação); as regras colocam apenas questões de validade (se elas não são corretas devem ser alteradas). ${ }^{9}$

Já para Hart, em seu pós-escrito dirigido às críticas que seu pensamento recebeu, ensina que os princípios jurídicos diferem das demais regras de "tudo ou nada" porque, quando são aplicáveis, não obrigam a uma decisão, mas apontam para um decisão, ou afirmam uma razão que pode ser afastada. Comentando o pensamento de Ronald Dworkin, para quem os princípios jurídicos diferem das regras porque têm uma dimensão de peso, mas não de validade, e por isso quando em conflito com outro princípio de maior peso, um princípio poderá ser afastado, não logrando determinar a decisão, mas, não obstante irá sobreviver intacto para ser utilizado em outros casos em que possa prevalecer em concorrência com outro princípio de menor peso. Por outro lado, as regras são ou não são válidas, não têm essa dimensão de peso, e quando entrarem em conflito, apenas uma delas pode ser válida e a outra reformulada, de forma a tornar a decisão coerente com a sua concorrente, e, conseqüentemente, inaplicável ao caso dado. ${ }^{10}$

\footnotetext{
$9 \quad$ Ibid., p. 166-168.

10 HART, Herbert L. A. O conceito de direito. Trad. A. Ribeiro Mendes. Lisboa: Calouste Gulbenkian, 1986. p. 323 .
} 


\subsection{Conflito entre princípios}

Os princípios são gerais e abstratos e quando entram em choque uns com os outros teremos a denominada antinomia jurídica aparente, devendo ser realizado o juízo da ponderação ou da proporcionalidade dos interesses em jogo. Prevalecerá então o princípio de maior peso ou importância naquela circunstância em análise, afastando o de menor peso.

O conflito entre regras suscita a idéia das antinomias jurídicas próprias, já a colisão entre princípios, as antinomias jurídicas impróprias ou aparentes. Na primeira confrontação, a das regras entre si, exclui-se do sistema jurídico a regra conflitante, em face da incompatibilidade entre essa e outra norma situada no mesmo plano de validade, pertencentes ao mesmo ordenamento, ou seja, é na dimensão da validade que se resolve o problema entre as regras conflitantes. Essa decisão de afastar a regra incompatível dá-se por critérios afixados em cada ordem juridica (lex superior derogata lex inferiorem critério hierárquico, lex specialis derogata lex generalem - critério da especialidade, lex posterior derogata lex priorem - critério cronológico). ${ }^{11}$

Para Alexy ${ }^{12}$ um conflito entre regras somente pode ser resolvido se uma cláusula de exceção, que remova o conflito, for introduzida uma regra ou pelo menos se uma das regras for declarada nula. Já a colisão entre princípios - antinomias jurídicas impróprias - nao conduz a exclusao da ordem juridica de uma das normas conflitantes. Há incompatibilidade, porém nao exclusão. Nesta situação far-se-a um juizo de ponderação, aplicando o princípio de maior peso e importância ${ }^{13}$. Desta forma, o principio que não foi

11 ESPÍNDOLA, Ruy Samuel. Conceito de princípios constitucionais. São Paulo: Editora Revista dos Tribunais, 2002. p. 73-74.

12 BONAVIDES, Paulo. Curso de direito constitucional. São Paulo: Malheiros, 1993. p. 251.

13 Sobre colisão entre princípios e aplicação do principio da proporcionalidade, já se manifestou o Superior Tribunal de Justiça (STJ), no MS 9745 / DF; MANDADO DE SEGURANÇA 2004/0078453-2 em 27/10/2004: Ementa: MANDADO DE SEGURANÇA. CONTROLADORIA-GERAL DA UNIÃO CGU.PROCEDIMENTO FISCALIZATÓRIO EM MUNICÍPIOS. DIVULGAÇÃO DE INFORMAÇÕES PRELIMINARES NA PÁGINA DA INTERNET. LEGALIDADE. INEXISTÊNCIA DE OFENSA AOS PRINCÍPIOS DA AMPLA DEFESA E DO CONTRADITÓRIO. PROPORCIONALIDADE NA APLICAÇÃO DAS REGRAS CONSTITUCIONAIS. PREVALÊNCIA DO PRINCÍPIO DA PUBLICIDADE. TUTELA DOS INTERESSES DA SOCIEDADE. 1. Trata-se de mandado de segurança preventivo, com pedido de liminar, impetrado pelo MUNICÍPIO DE PINDOBAÇU, contra ato a ser praticado pelo Sr. Ministro de Estado do Controle e da Transparência, consubstanciado na publicação - no site de internet da Controladoria-Geral da União - de relatório preliminar que aponta irregularidades na utilização de verba federal destinada à utilização do impetrante. 2. Sustenta o impetrante que essa medida administrativa - publicação do relatório - caracteriza ato ilegal e abusivo, na medida em que antecipa juízo de valor que somente será alcançado pelo trabalho que vier a ser desenvolvido pelos órgãos competentes para o exame do mencionado relatório, uma vez que a Controladoria não detém competência para o julgamento das informações por ela colhidas, desiderato que é de responsabilidade do Tribunal de Contas da União, do Ministério Público ou ainda dos órgãos federais que autorizaram as verbas ao Município. 3. Inexistência, todavia, do direito vindicado, tampouco da sua liquidez e certeza, vez que o exercício de qualquer cargo ou função pública, notadamente o de chefe do Poder Executivo municipal, demanda a necessária submissão aos princípios constitucionais da legalidade, impessoalidade, moralidade, publicidade e eficiência, dentre 
aplicado e afastado em virtude da importância e do peso maior do outro, não é excluído da ordem jurídica, podendo vir a ser aplicado em outra situação. A colisão entre princípios verifica-se na dimensão do peso de cada um, já que apenas princípios válidos podem colidir entre si. $^{14}$

\subsection{Força normativa dos princípios}

Atualmente a força normativa dos princípios encontra-se assentada na doutrina e na jurisprudência, através de sua concretização normativa. Mas para chegar ao status de normatividade, os princípios jurídicos passaram por um trabalho de elaboração metodológica desenvolvida pela Ciência Jurídica, se segundo Bonavides, remonta às disputas epistemológicas entre as correntes do pensamento jurídico do jusnaturalismo e do positivismo jurídico, esta última remodelada, sendo denominada pós-positivismo jurídico.

Para Paulo Bonavides, a juridicidade ou normatividade dos princípios passou por três fases distintas: a fase jusnaturalista, a positivista e a pós-positivista. Senão vejamos:

(1) A fase jusnaturalista posicionou os princípios jurídicos em esfera abstrata e metafísica. Eram reconhecidos como inspiradores de um ideal de justiça, cuja eficácia estava cingida numa dimensão ético-valorativa do direito. Desta forma, eram considerados axiomas jurídicos ou normas estabelecidas pela reta razão, ou seja, são normas universais de bem obrar. São princípios de justiça, constitutivos de um direito ideal e em definitivo eram tidos como um conjunto de verdades objetivas da lei divina e humana.

(2) Na fase juspositivista os princípios entram nos Códigos como fonte normativa subsidiária da inteireza dos textos legais. São encarados como verdadeiras válvulas de segurança, garantindo o reinado absoluto das leis. Não são encarados como superiores às leis, mas delas deduzidos, para suprirem os vazios normativos que elas não puderem prever. São considerados como fonte subsidiária, ou seja, são fontes de integração do direito, quando ocorrerem vazios legais.

(3) A terceira fase, a do pós-positivismo, inaugura a hegemonia axiológico-normativa dos princípios, que agora positivados nos novos textos constitucionais, assentam

outros requisitos. 4. Hipótese em que deve se aplicar a proporcionalidade entre as regras constitucionais e a hierarquização do bem a merecer a tutela da jurisdição. Na espécie, o objetivo colimado pelo impetrante não prevalece sobre o interesse social que a impetrada busca assegurar. 5. Segurança denegada. (Grifos nosso). Superior Tribunal de Justiça (STJ). Disponível em http://www.stj.gov.br/SCON/jurisprudencia/doc, capturado em 22/ 05/2006.

14 GRAU, Eros Roberto. A ordem econômica na Constituição de 1988. São Paulo: Editora RT, 1990. p. $115-$ 116. 
os principais padrões pelos quais se investiga a compatibilidade da ordem jurídica aos princípios fundamentais de escalão constitucional; aos princípios que dão fundamento axiológico e normativo ao ordenamento jurídico ${ }^{15}$. Nesta fase, segundo Bonavides, os princípios jurídicos conquistam a dignidade de normas jurídicas vinculantes, vigentes e eficazes para muito além da atividade integratória do direito. Isso se deveu, não só ao valioso trabalho teórico de juristas como Ronald Dworkin, mas também aos trabalhos de publicistas alemães, espanhóis e italianos, destacando-se o nome do alemão Robert Alexy. ${ }^{16}$

Em sua obra, Teoria do Ordenamento Jurídico, Norberto Bobbio, disserta sobre a normatividade dos princípios jurídicos: Os princípios gerais são, a meu ver, normas fundamentais ou generalíssimas do sistema, as normas mais gerais. O nome de princípios induz em engano, tanto que é velha questão entre juristas se os princípios são ou não são normas. Para mim, não há dúvida: os princípios gerais são normas como todas as demais. E esta é a teses sustentada pelo estudioso que mais amplamente se ocupou da problemática, ou seja, Crisafulli. Para sustentar que os princípios são normas, os argumentos vêm a ser dois e ambos válidos: antes de tudo, se são normas aquelas das quais os princípios gerais são extraídos, através de um procedimento de generalização sucessiva, não se vê por que não devam ser normas também eles: se abstraio de espécies animais, obtendo sempre animais, e não flores ou estrelas. Em segundo lugar, a função para a qual são abstraídos e adotados é aquela mesma que é cumprida por todas as normas, isto é, a função de regular um caso. Para regular um comportamento não regulado, é claro: mas agora servem ao mesmo fim para que servem as normas expressas. E por que então não deveriam ser normas? ${ }^{17}$

\section{Conteúdo do princípio da igualdade}

A Constituição Federal brasileira de 1988 atribui ao princípio da igualdade dois conteúdos distintos e complementares: a não-discriminação injusta, que seria o conteúdo positivo do princípio da igualdade e a promoção da igualdade, que seria o conteúdo negativo do princípio.

Em relação ao conteúdo do princípio da igualdade, de acordo com J. J. Calmon de Passos, pode-se dizer que:

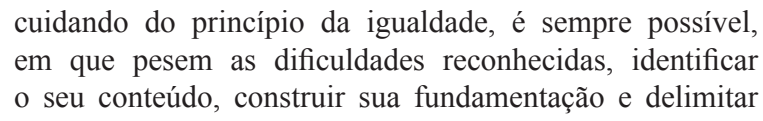

\footnotetext{
15 BONAVIDES, Paulo. op. cit., p. 237.

16 BONAVIDES, Paulo. op. cit., p. 237-238.

17 BOBBIO, Norberto. Teoria do ordenamento jurídico. Brasília: UnB, 1989.
} 
seu alcance. Partindo-se do homem e de sua necessária sociabilidade temos condições de definir o que os faz iguais ou reclama que como iguais sejam tratados. Já no particular da não discriminação, comportamento idêntico é impensável, porque esse princípio não tem consistência própria, mas é uma aparente derrogação do princípio da igualdade, em face da inelutável necessidade prática de termos que tratar diferentemente os homens para igualá-los. Delimitar a diferenciação aceitável, porque compensadora, da que não comporta acolhida no sistema jurídico constitucional, é o que denominamos, com certa improbidade, de princípio de não discriminação, quando se trata não de um princípio, mas de um desdobramento do princípio da igualdade, em face da essencial desigualdade dos homens da necessidade politicamente essencial, em termos de modernidade, de darlhes um tratamento igualitário. ${ }^{18}$

Desta forma, ter-se-ia que o limite do conteúdo do princípio da igualdade é de constituir uma sociedade essencialmente meritocrática, todavia observando que ao nascer, cada pessoa encontra-se dentro da sociedade numa posição particular, sendo que a natureza desata posição irá afetar consideravelmente suas perspectivas de vida, de acordo com a realidade social, que não poderia ser ignorada.

Respondendo a realidade social, o Estado não poderia ficar em uma atitude de abstenção, meramente anti-discriminatória, pois estar-se-ia indo contra com os ditames da justiça social (artigo $170 \mathrm{da} \mathrm{CF} / 88$ ) e da tutela da dignidade da pessoa humana (artigo $1^{\circ}$, inciso III da CF/88), consagrados no sistema constitucional brasileiro. Optou-se então pela adoção de uma atitude intervencionista e dirigista, com a adoção de barreiras que se opõem à materialização da igualdade.

\subsection{Conteúdo positivo do princípio da igualdade}

O conteúdo positivo do princípio da igualdade tem sustentação em três espécies de regras constitucionais:

(a) A primeira de teor rigorosamente igualitarista, atribuindo ao Estado o dever de abolir a marginalização e as desigualdades, destacando-se:

"artigo $3^{\circ}$, inciso III - erradicar a (....) marginalização e reduzir as desigualdades sociais...”

"artigo 23, inciso X - combater (...) os fatores de marginalização;”

18 PASSOS, J. J. Calmon de. O princípio de não discriminação. Jus Navigandi, Teresina, ano 6, n. 57, jul. 2002. Disponível em: <http://jus2.uol.com.br/doutrina/texto.asp?id=2990>. Acesso em: 13 set. 2006. 
"artigo 170, inciso VII - redução das desigualdades (...) sociais;”

(b) A segunda espécie fixando textualmente prestações positivas, destinadas à promoção e integração dos segmentos desfavorecidos:

"artigo $3^{\circ}$, inciso IV - promover o bem de todos, sem preconceitos de origem, raça, sexo, cor, idade e quaisquer outras formas de discriminação;"

"artigo 23, inciso X - combater as causas da pobreza e os fatores de marginalização, promovendo a integração social dos setores desfavorecidos;"

"artigo 227, inciso II - criação de programas (...) de integração social dos adolescentes portadores de deficiência;"

(c) A terceira espécie de norma constitucional estabelecendo de forma textual uma discriminação justa como forma de compensar a desigualdade de oportunidades, ou, em alguns casos, fomentar o desenvolvimento de setores considerados prioritários:

"artigo $7^{\circ}$, inciso XX - proteção do mercado de trabalho da mulher, mediante incentivos específicos, nos termos da lei";

“artigo 37, inciso VIII - a lei reservará percentual dos cargos e empregos públicos para as pessoas portadoras de deficiência e definirá os critérios de sua admissão;"

“artigo 145, $\S 1^{\circ}$ Sempre que possível, os impostos terão caráter pessoal e serão graduados segundo a capacidade econômica do contribuinte...;",

"artigo 170, inciso IX - tratamento favorecido para as empresas de pequeno porte constituídas sob as leis brasileiras e que tenham sua sede e administração no País;"

“artigo 179. A União, os Estados, o Distrito Federal e os Municípios, dispensarão às microempresas e às empresas de pequeno porte, assim definidas em lei, tratamento jurídico diferenciado, visando a incentivá-las pela simplificação de suas obrigações administrativas, tributárias, previdenciárias e creditícias, ou pela eliminação ou redução destas por meio de lei”.

Já no plano infraconstitucional ter-se-ia os casos previstos:

(1) Decreto-Lei n. 5.452/43 (CLT), que prevê, em seu art. 354, cota de dois terços de brasileiros para empregados de empresas individuais ou coletivas;

(2) Decreto-Lei n. 5.452/43 (CLT), que estabelece, em seu art. 373-A, a adoção de políticas destinadas a corrigir as distorções responsáveis pela desigualação de direitos entre homens e mulheres; 
(3) Lei n. 8.112/90, que prescreve, em art. $5^{\circ}, \S 2^{\circ}$, cotas de até $20 \%$ para os portadores de deficiências no serviço público civil da união;

(4) Lei n. 8.213/91, que fixou, em seu art. 93, cotas para os portadores de deficiência no setor privado;

(5) Lei n. 8.666/93, que preceitua, em art. 24, inc. XX, a inexigibilidade de licitação para contratação de associações filantrópicas de portadores de deficiência;

(6) Lei n. 9.504/97, que preconiza, em seu artigo $10, \S 2^{\circ}$, cotas para mulheres nas candidaturas partidárias.

\subsection{Conteúdo negativo do princípio da igualdade}

A dimensão negativa do princípio da igualdade está previsto na primeira parte do caput do art. $5^{\circ}$ da Constituição Federal, de 1988, ao afirmar que todos são iguais perante a lei, sintetizando desta forma a sua dimensão negativa.

Esse conteúdo negativo, que impõe uma obrigação negativa, ou seja, uma abstenção, um papel passivo, uma obrigação de não-fazer: não-discriminar, que irá desdobrar-se num amplo leque de regras constitucionais que visam coibir a ocorrência de discriminação injusta, como as regras proibitivas de violação de direitos fundada em critérios de origem, cor, raça, sexo, idade, estado civil, porte de deficiência, credo religioso, convicção filosófica ou política, tipo de trabalho ou natureza de filiação do individuo.

4. Princípios da não-discriminação, da igualdade e da dignidade da pessoa humana

O princípio da não-discriminação é um desdobramento do princípio da igualdade, e segundo J. J. Calmon de Passos é insuscetível de ser construído a partir dele próprio ou de uma direta referência ao homem. É sempre um consectário ou reflexo do princípio da igualdade, como seja entendido e positivado, ao qual se prende umbilicalmente. ${ }^{19}$

Desta forma, o princípio de não discriminação, tido como um desdobramento do princípio da igualdade, é aplicado em face da essencial desigualdade dos homens, tem por base dar-lhes um tratamento igualitário, na medida que de suas desigualdades.

O princípio da igualdade ou isonomia veda as diferenciações arbitrárias, as discriminações absurdas, pois, o tratamento desigual nos casos desiguais, na medida em que se desigualam, é exigência tradicional do próprio conceito de Justiça, pois o que realmente protege são certas finalidades, somente se tendo por lesado o princípio

19 PASSOS, J. J. Calmon de. O princípio de não discriminação. Jus Navigandi, Teresina, ano 6, n. 57, jul. 2002. Disponível em: <http://jus2.uol.com.br/doutrina/texto.asp?id=2990>. Acesso em: 13 set. 2006. 
constitucional quando o elemento discriminador não se encontra a serviço de uma finalidade acolhida pelo direito. ${ }^{20}$

Segundo Celso A. Bandeira de Mello, o princípio da isonomia, reveste-se de auto-aplicabilidade, pois é um postulado fundamental de nossa ordem político-jurídica, não sendo suscetível de regulamentação ou de complementação normativa. Segundo o autor:

O princípio da isonomia ou igualdade, cuja observância vincula, incondicionalmente, todas as manifestações do Poder Público - deve ser considerado, em sua precípua função de obstar discriminações e de extinguir privilégios, sob duplo aspecto: o da igualdade na lei; b) o da igualdade perante a lei. A igualdade na lei - que opera numa fase de generalidade puramente abstrata - constitui exigência destinada ao legislador que, no processo de sua formação, nela não poderá incluir fatores de discriminação, responsáveis pela ruptura da ordem isonômica. A igualdade perante a lei, contudo, pressupondo lei já elaborada, traduz imposição destinada aos demais poderes estatais, que, na aplicação da norma legal, não poderão subordiná-la a critérios que ensejem tratamento seletivo ou discriminatório. $^{21}$

Em relação ao princípio da igualdade, Canotilho adverte que haverá observância da igualdade:

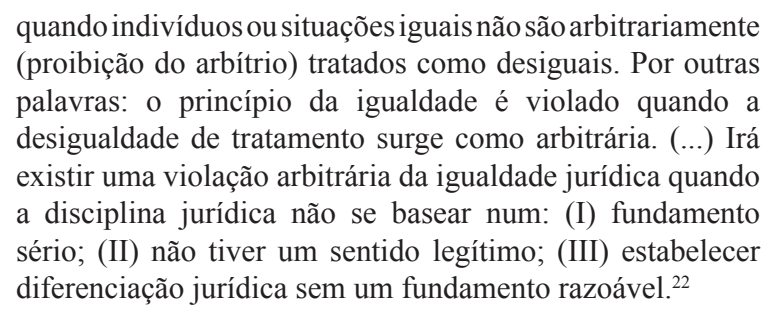

Celso Antonio Bandeira de Mello, estabelece que haverá inobservância do princípio constitucional da igualdade ou isonomia nas seguintes situações:

I - A norma singulariza atual e definitivamente um destinatário determinado, ao invés de abranger uma categoria de pessoas, ou uma pessoa futura indeterminada.

II - A norma adota como critério discriminador, para fins de diferenciação de regimes, elemento não residente nos fatos, situações ou pessoas por tal modo desequiparadas. É o que ocorre quando pretende tomar o fator tempo - que não descansa no objeto - como critério diferencial.

\footnotetext{
20 MORAES, Alexandre de. Direito constitucional. São Paulo: Editora Atlas, 2006. p. 31.

21 MELlo, Celso A. Bandeira de. Revista de Direito Administrativo. Rio de Janeiro: Fundação Getulio Vargas, n. 183. p.146.

22 CANOtilho, J. J Gomes. Direito constitucional e teoria da constituição. Coimbra: Almedina. 1995. p. 401.
} 
III - A norma atribui tratamento jurídicos diferentes em atenção ao fator de discrímen adotado que, entretanto, não guarda relação de pertinência lógica com a disparidade de regimes outorgados.

IV - A norma supõe relação de pertinência lógica existente em abstrato, mas o discrímen estabelecido conduz a efeitos contrapostos ou de qualquer modo dissonantes dos interesses protegidos constitucionalmente.

V - A interpretação da norma extrai dela distinções, discrímens, desequiparações que não foram professadamente assumidos por ela de modo claro, ainda que por via implícita. $^{23}$

O valor da dignidade da pessoa humana bem como os direitos e garantias fundamentais constituem princípios constitucionais que incorporam as exigências de justiça e dos valores éticos, conferindo desta forma suporte axiológico a todo o sistema jurídico brasileiro. ${ }^{24}$

Segundo José Afonso da Silva a dignidade da pessoa humana é um valor supremo que atrai o conteúdo de todos os direitos fundamentais do homem, desde o direito à vida. ${ }^{25}$ Nesse sentido, quando a Constituição Federal elencou no seu artigo $1^{\circ}$, inciso III, a dignidade da pessoa humana como um dos princípios fundamentais da República consagrou a obrigatoriedade da proteção máxima à pessoa por meio de um sistema jurídico-positivo formado por direitos fundamentais e da personalidade humana, garantindo assim o respeito absoluto ao indivíduo, propiciando-lhe uma existência plenamente digna e protegida de qualquer espécie de ofensa, quer praticada pelo Estado, quer pelo particular. ${ }^{26}$

\section{Os Direitos Humanos e os Direitos Fundamentais}

O termo "Homem", utilizado como genérico, provém do latim homo, que designa todo ser humano sem distinção alguma (notadamente de sexo); o termo "direitos" empregado em um sentido subjetivo refere-se a prerrogativas juridicamente protegidas. A expressão Direitos Humanos designa, pois, prerrogativas próprias ao ser humano e regidas por regras; ela deriva da expressão "direitos naturais do homem"; abrangendo em

23 MELLO, Celso Antonio Bandeira de. Conteúdo jurídico do princípio da igualdade. São Paulo: Editora Malheiros, 2002. p. 47.

24 PIOVESAN, Flávia. A proteção dos Direitos Humanos no sistema constitucional brasileiro. Revista de Direito Constitucional e Internacional. São Paulo: Revista dos Tribunais, n. 45, a. 11, out./dez. 2003. p. 221.

25 SILVA, José Afonso da. Curso de direito constitucional positivo. São Paulo: Revista dos Tribunais, 1990. p. 93.

26 ALMEIDA NETO, Amaro Alves de. Dano existencial - a tutela da dignidade da pessoa humana. Revista de Direito Privado. São Paulo, n. 24, ano 6, out./dez. 2005. p. 26. 
sua origem essencialmente "as liberdades", estendendo-se progressivamente seu campo a prerrogativas de ordem social e de alcance coletivo. ${ }^{27}$

Os Direitos do Homem são os ideais universais a serem alcançados por todos os povos e nações, tal qual formulado na Declaração Universal dos Direitos do Homem, de 10.12.1948, em que:

CONSIDERANDO que o reconhecimento da dignidade inerente a todos os membros da familia humana e seus direitos iguais e inalienáveis é o fundamento da liberdade, da justiça e da paz no mundo, CONSIDERANDO que o desprezo e o desrespeito pelos direitos do homem resultaram em atos bárbaros que ultrajaram a consciência da Humanidade, e que o advento de um mundo em que os homens gozem de liberdade de palavra, de crença e da liberdade de viverem a salvo do temor e da necessidade, CONSIDERANDO ser essencial que os direitos do homem sejam protegidos pelo império da lei, para que o homem não seja compelido, como último recurso, à rebelião contra a tirania e a opressão, CONSIDERANDO ser essencial promover o desenvolvimento de relações amistosas entre as nações, CONSIDERANDO que os povos das Nações Unidas reafirmaram, na Carta, sua fé nos direitos do homem e da mulher, e que decidiram promover o progresso social e melhores condições de vida em uma liberdade mais ampla, CONSIDERANDO que os Estados Membros se comprometeram a promover, em cooperação com as Nações Unidas, o respeito universal aos direitos e liberdades fundamentais do homem e a observância desses direitos e liberdades, CONSIDERANDO que uma compreensão comum desses direitos e liberdades é da mais alta importância para o pleno cumprimento desse compromisso,

A Assembleia Geral das Nações Unidas proclama a presente "Declaração Universal dos Direitos do Homem" como o ideal comum a ser atingido por todos os povos e todas as nações, com o objetivo de que cada indivíduo e cada órgão da sociedade, tendo sempre em mente esta Declaração, se esforce, através do ensino e da educação, por promover o respeito a esses direitos e liberdades, e, pela adoção de medidas progressivas de caráter nacional e internacional, por assegurar o seu reconhecimento e a sua observância universais e efetivos, tanto entre os povos dos próprios Estados Membros, quanto entre os povos dos territórios sob sua jurisdição.

Desta forma, os direitos dumanos são direitos universais, não dependem da positivação interna e tem um objetivo de ser concretizado em todas as nações, numa perspectiva cosmopolita e de universalidade.

27 ARNAUD, André-Jean. Dicionário Enciclopédico de Teoria e de Sociologia do Direito. Rio de Janeiro: Editora Renovar, 1999. p. 271-272. 


\section{Na definição de Celso D. de Albuquerque MELLO, ${ }^{28}$}

os direitos do homem são aqueles que estão consagrados nos textos internacionais e legais, não impedindo que novos direitos sejam consagrados no futuro. Considera que os já existentes não podem ser retirados, vez que são necessários para que o homem realize plenamente a sua personalidade no momento histórico atual. Se alguns vêm da própria natureza humana que construímos, outros advêm do desenvolvimento da vida social. Na verdade, o homem nunca existiu isoladamente.

$\mathrm{Na}$ definição de André-Jean Arnaud ${ }^{29}$ os Direitos Humanos podem ser definidos como o conjunto de princípios e de normas fundamentadas no reconhecimento da dignidade inerente a todos os seres humanos e que visam assegurar o seu respeito universal e efetivo.

Canotilho $^{30}$ faz a distinção entre "direitos do homem", como aqueles originários da natureza humana, com caráter inviolável, intemporal e universal, válidos para todos os povos e "direitos fundamentais" como aqueles objetivamente vigentes numa ordem jurídica concreta, isto é, direitos do homem, jurídico-institucionalmente garantidos e limitados espacio-temporalmente.

Estabelece também um duplo aspecto em relação aos direitos fundamentais: direitos fundamentais formalmente constitucionais, que seriam aqueles enunciados e protegidos por normas com valor constitucional formal (normas que têm a forma constitucional), e outros que a Constituição admite como tais, constantes de leis e das regras aplicáveis do direito internacional, os quais seriam os direitos materialmente fundamentais. ${ }^{31}$

Nesse sentido, segundo Maria do Carmo Caminha, tem-se que:

Os Direitos Fundamentais e os Direitos Humanos não se confundem. Os Direitos Fundamentais constituem-se aqueles positivados pelo Estado, salvaguardados, tutelados nos limites do território nacional. São também denominados de individuais ou subjetivos, os quais podem abranger também os direitos sociais e políticos. Os Direitos Humanos por sua vez transcendem os limites de cada Estado. São também denominados naturais. São inerentes à existência do homem, valendo por si mesmos, independentemente

28 MELLO. Celso D. de Albuquerque. Direitos humanos e conflitos armados. Rio de Janeiro: Editora Renovar, 1997. p. 5.

29 ARNAUD, André-Jean. Dicionário Enciclopédico de Teoria e de Sociologia do Direito. Rio de Janeiro: Editora Renovar, 1999.

30 CANOTILHO, José Joaquim Gomes. Direito constitucional e teoria da constituição. 2. ed. Coimbra: Almedina, 2002. p. 418-420.

31 Ibid., p. 418-420. 
de positivação. Estão acima dos interesses meramente nacionais, merecendo atenção do Direito Internacional, onde a solidariedade substitui o individualismo. ${ }^{32}$

Segundo Vicente Barreto, o emprego da expressão "Direitos Humanos", reflete essa abrangência e a consequente imprecisão conceptual com que tem sido utilizada. A expressão pode referir-se a situações sociais, políticas e culturais que se diferenciam entre si, significando muitas vezes manifestações emotivas face à violência e à injustiça; na verdade, a multiplicidade dos usos da expressão demonstra, antes de tudo, a falta de fundamentos comuns que possam contribuir para universalizar o seu significado e, em consequência a sua prática.

Em relação à terminologia, sustenta Vicente Barreto que:

inúmeros autores tomaram a expressão "direitos humanos" como sinônima de "direitos naturais", outros empregam a expressão como sendo o conjunto de direitos que assim se encontram definidos nos textos internacionais e legais, nada impedindo que novos direitos sejam consagrados no futuro, e, alguns também, referiam-se à idéia dos "direitos humanos" como sendo normas gerais, relativas à prática jurídica, que se expressariam através dos princípios gerais do direito. No pensamento social contemporâneo, encontramos a tentativa de identificar os direitos humanos fundamentais como a norma mínima das instituições políticas, aplicável a todos os Estados que integram uma sociedade dos povos politicamente justa, segundo o pensamento rawlsiano. ${ }^{33}$

Os Direitos Fundamentais, na definição de Robert Alexy, são essencialmente direitos do homem transformados em direito positivo. Os direitos fundamentais são, por um lado, elementos essenciais da ordem jurídica nacional respectiva. Por outro, porém, eles indicam além do sistema nacional. Nessa passagem do nacional deixa-se distinguir dois aspectos: um substancial e um sistemático. Os direitos fundamentais rompem, por razoes substanciais, o quadro nacional, porque eles, se querem satisfazer os requisitos que lhes podem ser postos, devem incluir os direitos do homem. Os direitos do homem têm, porém, independentemente de sua positivação, validez universal. ${ }^{34}$

Na definição de Robert Alexy, para serem fundamentais, os conteúdos desses direitos devem conter duas características ou requisitos essenciais, os quais são: a) a justiciabilidade, ou que sejam interesses e carências que, em geral, podem e devem

32 CAMINHA, Maria do Carmo Puccini. Os direitos humanos, os direitos fundamentais e a Constituição brasileira. Revista Forense, Rio de Janeiro, a. 98, v. 360, mar./abr. 2002. p. 71-72.

33 BARRETTO, Vicente de Paulo. Universalismo, multiculturalismo e direitos humanos. In: Direitos humanos no séc. XXI - parte I. Rio de Janeiro: IPRI, Fundação Alexandre Gusmão, 1998. p. 375.

34 ALEXY, Robert. Colisão de direitos fundamentais e realização de direitos fundamentais no Estado de direito democrático. Revista de Direito Administrativo, n. 217, jul-set., 1999. Editora Renovar e Fundação Getúlio Vargas. p. 67-69. 
ser protegidos e fomentados pelo direito; e, b) necessidade de seu respeito, proteção ou fomento fundamentado pelo direito.

Perez Luño estabelece uma delimitação histórica e conceitual dos direitos fundamentais, fazendo uma distinção entre Direitos Humanos e direitos fundamentais, termos muitas vezes utilizados como sinônimos. Segundo Perez Luño direitos fundamentais são os direitos positivados a nível interno e Direitos Humanos seriam os direitos naturais positivados nas declarações e convenções internacionais, assim como aquelas exigências básicas relacionadas com a dignidade, liberdade, igualdade da pessoa que não alcançou ainda um estatuto jurídico positivo. ${ }^{35}$

6. Os Direitos Humanos de primeira, segunda e terceira geração

Os Direitos Humanos podem ser classificados em uma escala cronológica de positivação e inserção nos ordenamentos jurídicos dos países em gerações de direitos. ${ }^{36}$ Desta forma a primeira geração de direitos seriam os direitos civis e políticos, os de segunda geração os direitos sociais, e, os de terceira geração, direito ao meio ambiente, direito urbanístico, entre outros.

Poder-se-ia fazer uma classificação dos direitos fundamentais:

(a) Os direitos de primeira geração: são aqueles que inauguram o movimento constitucionalista. Surgidos no século XVII, eles cuidam da proteção das liberdades públicas, ou seja, dos direitos e garantias clássicos, voltados para à preservação do direito à vida, à liberdade de ir e vir, à expressão, à religião, à associação, etc. Nesta fase, o Estado tem um dever de prestação negativa, isto é, um dever de não fazer, a não ser a respeitar as liberdades e garantias individuais.

(b) Os direitos de segunda geração: Surgiram após a Primeira Grande Guerra, visto que a liberdade total do homem, sem a intervenção estatal, não servia para a sua proteção integral. O capitalismo leva à exploração do homem, e frente a divisão do mundo em blocos antagônicos (capitalismo x comunismo), há a necessidade de intervenção do Estado, assegurando o bem-estar e a igualdade. Nesta fase

35 LUÑO, Antonio Perez. Los derechos fundamentales. Madrid: Tecnos, 1993. p. 44.

36 A questão da indivisibilidade dos Direitos Humanos é tão grave e séria que conduz alguns a criticarem de modo categórico a divisão de tais direitos em gerações. Antonio Augusto Cançado Trindade é um dos autores que não se cansa de repetir, em inúmeros trabalhos e livros, que na ordem internacional, a primeira geração é a de direitos sociais que se internacionalizaram através da Organização Internacional do Trabalho - OIT. Salienta o autor que os Estados podem ser induzidos a abandonar uma geração anterior e aplicar outra mais recente como se isto fosse modernidade. MELLO, Celso A. A proteção dos direitos humanos sociais nas Nações Unidas. Interesse Público, a. 4, n. 14, abr./jun. 2002. Porto Alegre: Notadez, 2002. p. 59. 
impõe-se ao Estado uma prestação positiva, qual seja, tomar providencias em favor do homem. Surgem, então, os direitos sociais, econômicos e culturais.

(c) Os direitos de terceira geração: surgidos a partir da Segunda Guerra Mundial, englobam os denominados direitos de solidariedade, voltados para a proteção da coletividade. As Constituições passam a incorporar em seus textos a preocupação com o meio ambiente equilibrado, a vida saudável e pacífica, o progresso, o avanço da tecnologia, etc. São direitos que irão materializar poderes de titularidade coletiva ou mesmo difusa.

(d) Os direitos de quarta geração: são identificados como aqueles que provocam alterações na vida e no comportamento dos homens, relativos à informática, à biodiversidade, à biotecnologia, etc.

Quanto às características dos direitos fundamentais, tem-se que são:

(a) Imprescritíveis: os direitos fundamentais não se subordinam ao tempo, ou seja, estão sempre prontos para serem exercidos pelo seu titular;

(b) Inalienáveis: não há possibilidade de renúncia a direito fundamental. Todos, o Estado e os homens, sob nenhum pretexto, podem deixar de observá-los;

(c) Universais: são reconhecidos em todo o mundo, ultrapassando fronteiras, independentemente do conceito de nacionalidade;

(d) Imutáveis: não podem sofrer alteração de cunho restritivo, ou seja, não admitem emendas tendentes, ainda que remotamente, a aboli-los.

\section{Afirma com o brilhantismo de sempre Celso LAFER, ${ }^{37}$}

os direitos humanos de primeira geração, que se baseiam numa clara demarcação entre Estado e não-Estado, com fundamentação no individualismo e no contratualismo vão ser positivados e declarados na Declaração da Virgínia e na Declaração Francesa de 1789. De acordo com Lafer, no plano do direito positivo o reconhecimento da importância dos direitos de Segunda geração já se encontra na Constituição Francesa de 1791 , que no seu Título $1^{\circ}$ previa a instituição do secours publics para criar crianças abandonadas, aliviar os pobres doentes e dar trabalho aos pobres inválidos que não o encontrassem. As primeiras constituições a assegurar os direitos de Segunda geração são a do México e a da Constituição de Weimar, sendo que no Brasil a primeira

37 LAFER, Celso. A reconstrução dos direitos humanos - um diálogo com o pensamento de Hannah Arendt. São Paulo: Companhia das Letras, 1988. p. 126-127. 
Constituição a garantir os direitos de Segunda geração foi a de 1934 .

No processo de asserção histórica dos Direitos Humanos, os direitos de terceira e de quarta geração, na linguagem da Organização das Nações Unidas (ONU), tem servido como ponto de apoio para a reivindicação dos desprivilegiados. A titularidade destes direitos seriam grupos humanos como a família, o povo, a nação, coletividades regionais ou étnicas e a própria humanidade, em detrimento do indivíduo em sua singularidade, podendo ser citado como exemplo, o direito de autodeterminação dos povos, expresso na Carta das Nações Unidas. ${ }^{38}$

No sistema jurídico brasileiro, sob o prisma da Constituição Federal de 1988, os direitos fundamentais podem ser classificados em:

(a) Direitos Individuais: são aqueles que delimitam a esfera de autonomia dos indivíduos, estabelecendo áreas onde estão a salvo da interferência do Estado e de outros homens $\left(\operatorname{artigo} 5^{\circ}\right.$ ).

(b) Direitos Coletivos: representam os direitos do homem integrante de uma coletividade $\left(\operatorname{artigo} 5^{\circ}\right)$.

(c) Direitos Sociais: reguladores das relações sociais e culturais, dividindo-se em direitos sociais propriamente ditos (artigo $6^{\circ}$ ) e direitos trabalhistas (artigo $7^{\circ}$ ao 11).

(d) Direitos à Nacionalidade: definidores da forma de obtenção, exercício e perda da nacionalidade (artigos 12 e 13).

(e) Direitos Políticos: definem a forma de participação no exercício do poder político (artigo 14 ao 17).

Para Maria Garcia, ${ }^{39}$ em nosso sistema constitucional, teríamos cinco direitos fundamentais básicos, de acordo com o artigo $5^{\circ}$, caput da Constituição Federal, os quais seriam: liberdade, igualdade, segurança e propriedade, constituindo estes o fundamento de todos os demais direitos consagrados, que pelos incisos do artigo $5^{\circ}$, quer pelos dispositivos sequenciais, do mesmo Título II, bem como de toda a Constituição Federal - dado que órgãos, bens, direitos, deveres, instituições refluem, todos, para um destinatário comum e único, em especial, o ser humano.

38 LAFER, Celso. op. cit., p. 130-131.

39 GARCIA, Maria. Mas, quais são os direitos fundamentais? Revista de Direito Constitucional e Internacional, São Paulo, a. 10, abr.jun. 2002. p. 122. 


\section{Conclusão}

Ao término deste trabalho monográfico, pode-se tecer as seguintes considerações finais:

(a) A noção e sentido de igualdade surgiram como um desejo humano de regular as relações sociais, sendo juridicizada nos idos das Revoluções Burguesas dos séculos XVIII e XIX e, primeiramente iam de encontro a todas as formas de privilégios e desigualdades materiais e formais então existentes.

(b) Os princípios da dignidade da pessoa humana e da isonomia ou igualdade são desdobramentos dos Direitos Fundamentais assegurados constitucionalmente, não sendo passíveis de modificações, constituindo desta forma verdadeiras clausulas pétreas.

(c) O princípio da igualdade ou isonomia desdobra-se em duas vertentes ou conteúdos: um conteúdo negativo, ou seja, de abstenção ou conteúdo um formal de estabelecer a igualdade de todos perante a lei; e, de um conteúdo positivo, onde se exige a atuação do Estado através de leis e regras disciplinando as formas de não-discriminação frente às desigualdades existentes entre os indivíduos.

(d) O valor da dignidade humana atrai e se vincula a todo o elenco dos Direitos Fundamentais, constitucionalmente assegurados. Tais direitos são o resultado de lutas e reivindicações de grupos e indivíduos ao longo dos tempos e concretizam um processo histórico de afirmação e consolidação em gerações de direitos, concretizando uma ordem jurídica democrática, de participação e de um Estado de Direito.

São Paulo, setembro de 2012.

\section{Referências}

ALEXY, Robert. Colisão de direitos fundamentais e realização de direitos fundamentais no Estado de direito democrático. Revista de Direito Administrativo, n. 217, jul./set. 1999. Editora Renovar e Fundação Getúlio Vargas.

ARNAUD, André-Jean. Dicionário Enciclopédico de Teoria e de Sociologia do Direito. Rio de Janeiro: Editora Renovar, 1999.

ATALIBA, Geraldo. República e Constituição. São Paulo: Malheiros Editores, 1998.

BARRETTO, Vicente de Paulo. Universalismo, Multiculturalismo e Direitos Humanos. In: Direitos humanos no século XXI - parte I. Rio de Janeiro: IPRI, Fundação Alexandre Gusmão, 1998. 
BOBBIO, Norberto. Teoria do ordenamento jurídico. Brasília: UnB, 1989.

BONAVIDES, Paulo. Curso de direito constitucional. São Paulo: Malheiros, 1993.

CAMINHA, Maria do Carmo Puccini. Os direitos humanos, os direitos fundamentais e a Constituição brasileira. Revista Forense, Rio de Janeiro: Editora Forense, a. 98, v. 360, mar./abr. 2002.

CANOTILHO, José Joaquim Gomes. Direito constitucional e teoria da constituição. 2. ed. Coimbra: Almedina, 2002.

CANOTILHO, José Joaquim Gomes. Curso de direito constitucional. Coimbra: Almedina, 1993.

CANOtilho, J. J Gomes. Direito constitucional e teoria da constituição. Coimbra: Almedina. 1995.

COVRE, Maria de Lourdes Manzini. O que é cidadania. São Paulo: Brasiliense, 1993.

ESPÍNDOLA, Ruy Samuel. Conceito de princípios constitucionais. São Paulo: Editora Revista dos Tribunais, 2002.

GARCIA, Maria. Mas, quais são os direitos fundamentais? Revista de Direito Constitucional e Internacional, São Paulo: Editora Revista dos Tribunais, a. 10, abr./jun. 2002.

GRAU, Eros Roberto. A ordem econômica na constituição de 1988. São Paulo: Editora Revista dos Tribunais, 1990.

HART, Herbert L. A. O conceito de direito. Trad. A. Ribeiro Mendes. Lisboa: Calouste Gulbenkian, 1986.

LAFER, Celso. A reconstrução dos direitos humanos: um diálogo com o pensamento de Hannah Arendt. São Paulo: Companhia das Letras, 1988.

LUÑO, Antonio Perez. Los derechos fundamentales. Madrid: Tecnos, 1993.

MELLO, Celso A. A proteção dos direitos humanos sociais nas Nações Unidas. Interesse Público, Porto Alegre: Notadez, a. 4, n. 14, abr./jun. 2002.

MELlO, Celso Antonio Bandeira de. Conteúdo jurídico do princípio da igualdade. São Paulo: Editora Malheiros, 2002. . Revista de Direito Administrativo, Rio de Janeiro: Fundação Getulio Vargas, n. 183. p.146.

MELLO. Celso D. de Albuquerque. Direitos humanos e conflitos armados. Rio de Janeiro: Editora Renovar, 1997.

MORAES, Alexandre de. Direito constitucional. São Paulo: Editora Atlas, 2006.

NETO, Amaro Alves de Almeida. Dano existencial - a tutela da dignidade da pessoa humana. Revista de Direito Privado, São Paulo, a. 6, n. 24, out./dez. 2005. 
PASSOS, J. J. Calmon de. O princípio de não discriminação. Jus Navigandi, Teresina, a. 6, n. 57, jul. 2002. Disponível em: <http://jus2.uol.com.br/doutrina/texto.asp?id=2990>. Acesso em: 13 set. 2006.

PIOVESAN, Flávia. A Proteção dos direitos humanos no Sistema Constitucional Brasileiro. In: Revista de Direito Constitucional e Internacional, São Paulo: Editora Revista dos Tribunais, a. 11, n. 45 , out./dez. 2003.

REALE, Miguel. Lições preliminares de direito. São Paulo: Editora Saraiva, 2001.

SILVA, José Afonso da. Curso de direito constitucional positivo. São Paulo: Editora Revista dos Tribunais, 1990.

TAVARES, Quintino L. C. Dworkin: princípios e diretrizes políticas: uma abordagem introdutória. Jusfilosofia, Florianópolis, jul. 2002. Disponível em: <http://br.geocities.com/jusfilosofia/ hermeneutica/dworkin1.html>. 